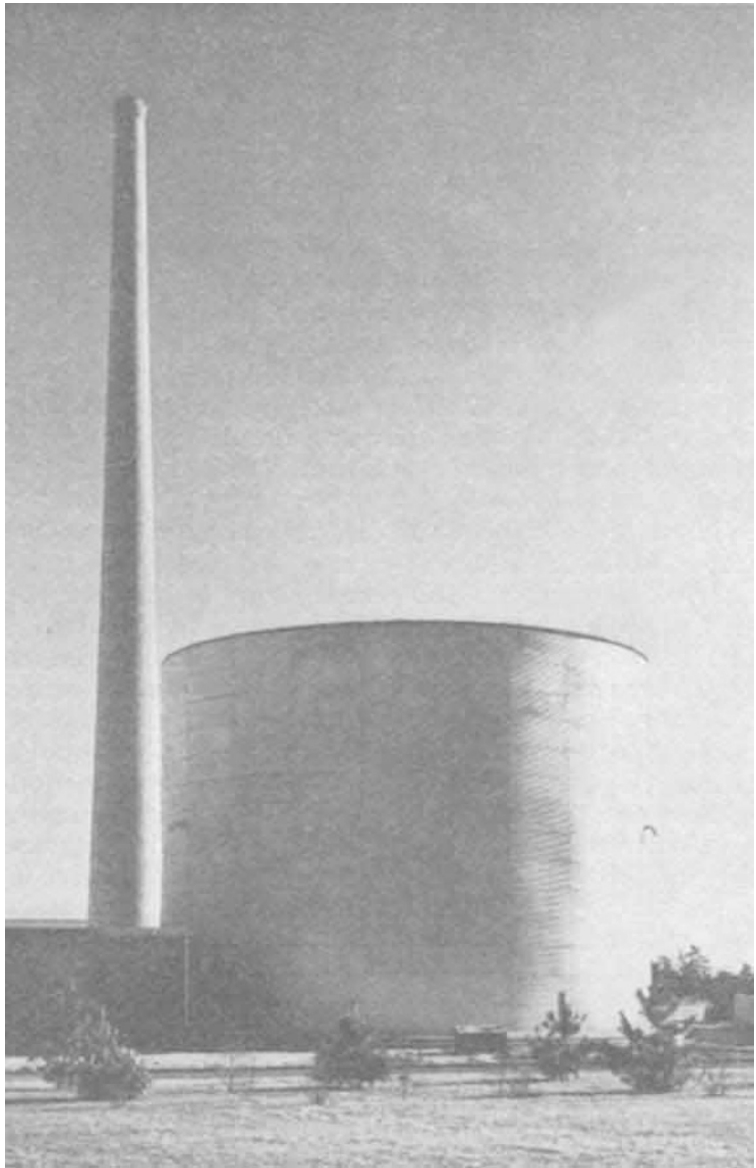

Fig. 2. Medical Research Reactor building. Cooling air for the reactor's graphite reflector is forced out of the 150 -ft. stack. The is connected to the main medical research complex, where the hospital and laboratories are located

did unexpectedly provide one of the most valuable of biological tracers-tritiated thymidine--a tagged compound which immediately enters the cycle of blood constituents, appearing rapidly in large mono- nuclear cells of the peripheral circulation. Similarly, an attempt to develop a therapeutic application of a rapidly decaying radioisotope of manganese becarne an avenue opening up a broad investigation into the presence and the behaviour of trace metals in health and disease.

Much of the research programme and future planning are directed toward the special medical problems to be met in the coming nuclear age; novel tools are coming into use and are being used in various ways. Among Brookhaven's 'big machines', noteworthy use has already been made of the reactor ; the high biological significance of neutrons of intermediate energy are being evaluated with a small cyclotron and a Van de Graaff accelerator ; the large cyclotron has provided deuteron beams as well as rare radioactive isotopes from heavy-particle bombardment; the Hot Laboratory has searched for desirable radioactive materials of special metabolic properties. The collaboration of the scientific and technical staff at Brookhaven illustrates the co-operation which has stimulated and assisted the work of the Medical Department in its first ten years, as it grew into the present research establishment with its unique capabilities. The Medical Research Center is thus an integral unit in a scientific community of some four hundred scientists and engineers working on all the problems of the utilization of nuclear energy:

Brookhaven National Laboratory is a civilian establishment operated under the guidance of nine major universities of the eastern seaboard of the United States; they supervise its administration through Associated Universities, Incorporated, which makes contracts with the U.S. Atomic Energy Commission for supporting funds. The Laboratory is in the centre of Long Island, 70 miles east of the middle of New York City on a campus converted from the Army's former Camp Upton. In the years from its inception in 1947, as a result of the foresight of leading scientists in the new fields which research with the big machines opened up, Brookhaven has become familiar ground to hundreds of visiting and collaborating scientists from many foreign lands, all of whom have been welcomed for their contribution to the 'peaceful uses of the atom'.

The work described here is supported by the United States Atomic Energy Commission.

\title{
OBITUARIES
}

\section{Prof. Arturo Duperier}

Prof. Arturo Duperier, who recently died in Madrid at the age of sixty-two, was distinguished by his pioneer researches into the variation of cosmic-ray intensity with time and with meteorological conditions. He began this work in 1938 when he came to work with me and my cosmic-ray colleagues in the Physical Laboratories of the University of Manchester. Soon after the outbreak of the Second World War, when the cosmic-ray group largely dispersed for war activities, he moved his apparatus to the Imperial College of Science and Technology, London, where Prof. George Thomson gave him laboratory space. In a small roorn near the top of the Royal College of Science building at South Kensington, Duperier set up a cosmic-ray recording set and ran it almost continuously throughout the War and bombing, and for some years afterwards.
It was the results obtained from this long period of very precise recording of the cosmic-ray intensity which provided Duperier with the material for his analysis. His most important technical achievement was the introduction and use of multiple correlation methods for disentangling the origin of the observed variations of cosmic-ray intensity. In this way he was able to show quantitatively how the observed dependence of the cosmic-ray intensity on temperature might be an effect due to the decay of muons in the atmosphere. By careful use of meteorological data obtained from radio-sonde observations, Duperier was able to locate the average height of production of the muons as about $16 \mathrm{~km}$. His method was to assume that the intensity varied both with the atmospheric pressure and with the unknown height of the muon-producing layer, and then to determine that value for the height of the laver for 
muon formation which gave the largest partial correlation coefficient.

This work demanded the meticulous analysis of a great amount of numerical data, at which Duperier was exceedingly expert. To facilitate this work he pioneered the use of business accounting machines for the analysis of cosmic-ray data. Later he refined his analytical method by introducing a three-term regression formula, and by this means obtained some indication-but no final proof - of the effect on the cosmic-ray intensity at sea-level of the pion decay in the upper atmosphere. This last work was carried out at Birkbeck College, where he moved soon after the War. In 1945 he gave the Guthrie Lecture to the Physical Society of London on the "Time Variations of Cosmic Rays".

Duperier was well known to cosmic-ray workers all over the world and regularly attended the biennial meetings of the International Cosmic Ray Conference, under the auspices of the International Union of Pure and Applied Physics, which has met since the War in Poland, India, France, Mexico and Italy. He will be greatly missed at the next meeting, planned for this summer in Moscow.

In 1951 Duperier returnod to Spain, where he resumed his professorship in the Faculty of Science in the University of Madrid. The loss to his country of the most distinguished Spanish atomic physicist of his generation is indeed great. He was awarded posthumously the Juan March Foundation prize of 500,000 pesetas for his outstanding scientific work.

Throughout Duperier's thirteen years in England, I was in close touch with his work, and came greatly to admire him not only as a scientist but also as a man of unbending rectitude of character. It is thus both as a fine scientist and as a close personal friend that I mourn his death. P. M. S. BLACKETT

\section{Prof. Pierre Fauvel}

Puerre Fauvel, professor in the University of Angers, who died on December 12, was one of the greatest systematic zoologists. A specialist on Polychaeta, a group with which his name will for ever be associated, Fauvel was supreme in his field. No one who preceded him and none of his contemporaries approached the brilliance of his systematic interpretation.

Fauvel was born at Cherbourg on October 8, 1866. Throughout the greater part of his professional life he was on the staff at the Catholic University of Angers, as professor of zoology for fifty-three years, with a term of office as dean of the Faculty of Science from 1942 until 1947.

In the early stages of his career, 1894-1909, Fauvel worked on human physiology, publishing papers on digestion and uric acid secretion, and on general marine biology. In the latter field he carried out research on the larval development of Arenicola, on the circulation in Amphictenidae, on otocysts and on nephridia. For his doctorate of science he published observations made on the Ampharetidae. During 1910-20, however, the trend towards systematics becomes more apparent, and Fauvel's first major work in this field was on collections of polychaetes made in the Mediterranean and Atlantic during cruises of l'Hirondelle and Princesse Alice, under the direction of Prince Albert of Monaco. There followed papers on collections from the Falkland Islands, Australia, West Africa and Madagascar in this period, and all indicated that a new and brilliant figure had arisen.

With the publication in 1923 and 1927 of his two volumes in the "Faune de France" series, Fauvel's position as the outstanding authority on polychaetes was established. He provided in these works a practical method of identifying almost 900 species, his sedulous preparation of keys, in particular, being of the greatest value. In the genera Harmothoë, Nereis and Serpula, numerous species, previously a jumbled assortment of specimens and populations, were reduced to a series of well-defined natural groups as clearly delineated as available knowledge allowed. For those most difficult of families, the Phyllodocidae and Syllidae, his consideration of the species concept brought order out of confusion. This same ability to define species and clarify taxonomic problems is evident in all the families, so that these volumes have been in continual use in practical marine courses throughout the world since publication, and will probably not be replaced, even by local faunal publications, for years to come. Marine ecologists and physiologists everywhere praise their value and no specialist would consider approaching a problem concerning polychaetes before first noting what Fauvel had to say. In addition, these two works represent models of how the perfect faunal study should be presented, and their extension to other groups (and other areas for Polychaeta) is of paramount importance.

In 1932 Fauvel's work on the polychaetes from the Indian Museum in Calcutta was published, and this also is an invaluable guide to the student and specialist. It was the first comprehensive publication on polychaetes from subtropical and tropical waters, and has been the basis of all later diagnoses of the Indo-Pacific fauna.

Through experience with populations from widely separated regions, Fauvel was able to demonstrate the cosmopolitan nature of many species and the unique endemic elements in particular areas. He was the first to recognize the occurrence in Europe of Mercierella enigmatica as an invasion, possibly from India, of a species capable of breeding in waters of low salinity. Since then, repeated records of this polychaete from harbours in western Europe have indicated how damaging the effects of its growth might be.

Honours, richly deserved, were paid to Fauvel by his native France; they included: Chevalier de la Légion d'honneur; Lauréat de l'Institut, Prix Savigny de l'Académie des Sciences; Membre de la Société Zoologique de France; Membre Correspondant du Muséum d'Histoire naturelle de Paris. It is indeed with pride that systematic zoologists can point to the career of Pierre Fauvel, for he always upheld the finest traditions of learning in pursuing his chosen subject to the utmost of his ability, and he gave to zoology some of the finest products of scholarship published during his life-time.

\section{Norman Tebrle}

\section{Dr. Herbert Hunter}

Dr. Herbert Hunter died on February 21 at Meldreth, near Cambridge, at the age of seventy-six, after a long and productive working life, during which he had made outstanding contributions to plant breeding, to agriculture and to the malting and brewing industries. He will always be remembered for his activities in these fields, and also as a dedicated research worker and student of his subject who kept his interest in his work up to the time of his death. 